\title{
Outcome quality standards in advanced ovarian cancer surgery
}

\author{
Antoni Llueca ${ }^{1,2,3^{*}}$ (D), Anna Serra ${ }^{1,2,3}$, Maria Teresa Climent ${ }^{1,2,3}$, Blanca Segarra ${ }^{1,2}$, Yasmine Maazouzi ${ }^{1,2}$, \\ Marta Soriano ${ }^{2,4}$, Javier Escrig ${ }^{2,3,5}$ and on behalf MUAPOS Working Group ${ }^{2}$
}

\begin{abstract}
Introduction: Advanced ovarian cancer surgery (AOCS) frequently results in serious postoperative complications. Because managing AOCS is difficult, some standards need to be established that allow surgeons to assess the quality of treatment provided and consider what aspects should improve. This study aimed to identify quality indicators (QIs) of clinical relevance and to establish their acceptable quality limits (i.e., standard) in AOCS.
\end{abstract}

Materials and methods: We performed a systematic search on clinical practice guidelines, consensus conferences, and reviews on the outcome and quality of AOCS to identify which Qls have clinical relevance in AOCS. We then searched the literature (from January 2006 to December 2018) for each QI in combination with the keywords of advanced ovarian cancer, surgery, outcome, and oncology. Standards for each QI were determined by statistical process control techniques. The acceptable quality limits for each QI were defined as being within the limits of the 99.8\% interval, which indicated a favorable outcome.

Results: A total of 38 studies were included. The Qls selected for AOCS were complete removal of the tumor upon visual inspection (complete cytoreductive surgery), a residual tumor of $<1 \mathrm{~cm}$ (optimal cytoreductive surgery), a residual tumor of $>1 \mathrm{~cm}$ (suboptimal cytoreductive surgery), major morbidity, and 5-year survival. The rates of complete cytoreductive surgery, optimal cytoreductive surgery, suboptimal cytoreductive surgery, morbidity, and 5year survival had quality limits of $<27 \%,<23 \%,>39 \%$, $>33 \%$, and $<27 \%$, respectively.

Conclusion: Our results provide a general view of clinical indicators for AOCS. Acceptable quality limits that can be considered as standards were established.

Keywords: Advanced ovarian cancer, Cytoreductive surgery, Outcome, Morbidity, Tumor, Quality indicator, Medical care

\section{Highlights}

- Quality indicators are described in advanced ovarian cancer surgery(AOCS)

- Acceptable quality limits are defined as standards in AOCS

\footnotetext{
* Correspondence: antonillueca@gmail.com

'Department of Obstetrics and Gynecology, University General Hospital of Castellón, Av Benicasim s/n, 12004 Castellón, Spain

${ }^{2}$ Multidisciplinary Unit of Abdominal Pelvic Oncology Surgery (MUAPOS),

University General Hospital of Castellón, Av Benicasim s/n, 12004 Castellón, Spain

Full list of author information is available at the end of the article
}

\section{Introduction}

Advanced ovarian cancer surgery (AOCS) aims to achieve maximal cytoreduction to increase survival, and even provide a definitive cure in some cases. Generally, this comprises an aggressive surgery that frequently results in serious postoperative complications, including patient's mortality or the impossibility of administration of subsequent oncological treatments. These complications can directly affect survival $[1,2]$.

A standard defines the range in which the level of quality reached in a certain process is acceptable, leading to establishment of the minimum allowable for an

(c) The Author(s). 2020, corrected publication December/2020. Open Access This article is licensed under a Creative Commons Attribution 4.0 International License, which permits use, sharing, adaptation, distribution and reproduction in any medium or format, as long as you give appropriate credit to the original author(s) and the source, provide a link to the Creative Commons licence, and indicate if changes were made. The images or other third party material in this article are included in the article's Creative Commons licence, unless indicated otherwise in a credit line to the material. If material is not included in the article's Creative Commons licence and your intended use is not permitted by statutory regulation or exceeds the permitted use, you will need to obtain permission directly from the copyright holder. To view a copy of this licence, visit http://creativecommons.org/licenses/by/4.0/. The Creative Commons Public Domain Dedication waiver (http://creativecommons.org/publicdomain/zero/1.0/) applies to the data made available in this article, unless otherwise stated in a credit line to the data. 
indicator. This implies comparing results in management of a specific disease through measurable, valid, and relevant indicators [3]. Because of the difficulty in managing advanced ovarian cancer (AOC), some standards need to be established that allow surgeons to assess the quality of the treatment provided and consider what aspects should improve, as well as compare their results with those of other groups. Investigation of quality surgical care is a multidimensional and complex challenge. The concept of quality may reflect different aspects of medical care, depending on the perspective under consideration. Structure (e.g., sufficient personnel, resuscitation cart availability, and working atmosphere), process (e.g., percentage of patients fulfilling the antibiotic prophylaxis protocol and patients with informed consent), and direct clinical outcomes (e.g., morbidity, mortality, and wound dehiscence) can be measured as a reflection of the quality of medical care [4].

Because of the complexity of AOCS, clinicians and surgeons require additional quality indicators (QIs) and their variability limits to determine what may be considered optimal or suboptimal treatment. This study aimed to identify QIs of clinical relevance and to establish their acceptable quality limits (AQLs) in AOCS according to a formal methodology.

\section{Materials and methods}

\section{Search strategy}

The research process was carried out in two parts. First, we needed to identify which QIs have clinical relevance in AOCS. Therefore, we performed a systematic search on clinical practice guidelines [5-7], consensus conferences [8], and reviews on the outcomes and quality of AOCS [9-15] that were published in MEDLINE/ PubMed, Embase, and the Cochrane Library.

Second, once a series of QIs were selected from this literature, a new search was performed for each QI in combination with the Medical Subject Heading keywords of advanced ovarian cancer, ovary, surgery, and oncology. Only papers published from January 2006 to December 2018 were included in this part of the investigation. Additional relevant studies were also selected from the references that were obtained through the search. For inclusion in the analysis, each evaluated QI had to be clearly mentioned in the text or be easily calculated from the data presented in the study. When studies included series with oncological and nononcological cases, careful selection of the results of the oncological cases was performed. When such selection was not possible, the paper was not included. When several studies were reported by the same institution, the study with the highest number of cases was selected. When studies included results from primary cytoreductive surgery and interval debulking surgery, careful selection of the primary cytoreductive surgery results was made. Studies were not included when such selection could not be performed. Despite being a retrospective review study of data from other authors, informed consent for the analysis was obtained from the Ethics and Research Committee (No. 02223/2019)

\section{Selection of QIs and studies}

Indicators were selected according to clinical relevance (factors that clearly affected the prognosis or the postoperative course) and frequency of appearance in the different studies to ensure a sufficient amount of data for evaluation. Each QI was investigated individually. Therefore, there were different numbers of studies and cases for each QI, depending on the information available for each item in particular. Publications were only included in our study if they presented a minimum number of 50 cases for each item. Series that reported national or collected databases with thousands of patients were excluded because these studies did not clearly reflect the results of any particular team or institution.

\section{Data collection and determination of standards}

Standards for each QI were determined by statistical process control (SPC) techniques. P-charts (categorical data) and X-charts (continuous data) were plotted to graphically represent the weighted average according to sample size as a quality standard. The studies were sorted in the charts according to the number of cases included in each series from a smaller to a larger volume of patients. According to Spiegelhalter et al. $[16,17]$ two limits represented by $99.8 \%$ confidence intervals $( \pm 3$ standard deviations [SDs]) and 95\% confidence intervals ( \pm 2 SDs) are calculated from the weighted average to establish variability limits. Any result outside of these limits significantly deviates from the weighted average ( $p$ $<0.002$ and $p<0.05$, respectively), and is considered out of control according to the SPC terminology. In our study, the AQLs for each QI were defined as being within the limits of the $99.8 \%$ interval, which indicated a favorable outcome. When a result was within the AQLs, it was considered to be within the standards.

\section{Results}

\section{Qls}

The QIs selected for AOCS were complete removal of the tumor upon visual inspection (complete cytoreductive surgery [CCS]), a residual tumor of $<1 \mathrm{~cm}$ (optimal cytoreductive surgery [OCS]), a residual tumor of $>1$ $\mathrm{cm}$ (suboptimal cytoreductive surgery [SCS]) [2], major morbidity (grades III and IV of Clavien-Dindo classification) [18], and 5-year survival. A total of 38 studies were identified (Table 1) [19-54]. 
Table 1 Primary cytoreductive surgery results in advanced ovarian cancer

\begin{tabular}{|c|c|c|c|c|c|c|c|c|c|}
\hline Author & $\mathrm{N}$ & CCS \% & CCS No & OCS \% & OCS No & SCS \% & SCS No & Major complications \% & 5 Year survival \% \\
\hline Du Bois et al. 2009 [19] & 3126 & 33.5 & 1046 & 31.2 & 975 & 35.3 & 1105 & & 39 \\
\hline Bookman et al. 2009 [20] & 4312 & 24.2 & 1044 & 45.1 & 1949 & 30.5 & 1319 & & \\
\hline Chang et al. 2012 [21] & 203 & 31 & 63 & 38 & 77 & 31 & 63 & 38 & 50 \\
\hline Chi et al. 2012 [22] & 285 & 24 & 69 & 47 & 134 & 29 & 82 & 10 & \\
\hline Colombo et al. 2008 [23] & 142 & 25.6 & 39 & 35.2 & 50 & 37.3 & 53 & 14 & 30 \\
\hline Fago-Olsen et al. 2014 [24] & 990 & 39 & 381 & 27 & 266 & 35 & 341 & 19 & 30 \\
\hline Fagotti et al. 2013 [25] & 148 & 62 & 92 & 27.7 & 41 & 10 & 15 & 8 & 30 \\
\hline Luyckx et al. 2012 [26] & 527 & 71 & 374 & 18 & 94 & 11 & 57 & & 50 \\
\hline Peiretti et al. 2010 [27] & 288 & 44 & 115 & 32 & 83 & 24 & 61 & 16 & 49 \\
\hline Rauh-Hain et al. 2012 [28] & 176 & 7.5 & 13 & 58 & 102 & 34 & 61 & 30 & 20 \\
\hline Rauh-Hain et al. 2013 [29] & 330 & 26 & 85 & 56 & 187 & 17.6 & 58 & & \\
\hline Rosen et al. 2014 [30] & 143 & 41.5 & 76 & 22.4 & 41 & 35.5 & 65 & & 50 \\
\hline Sehouli et al. 2010 [31] & 332 & 59.8 & 196 & 27.4 & 90 & 12.5 & 41 & 36.5 & 39 \\
\hline Tropé et al. 2012 [32] & 127 & 14 & 18 & 36 & 44 & 50 & 62 & 31 & 12 \\
\hline Vergote et al. $2010[1,33]$ & 336 & 19 & 64 & 22 & 70 & 60 & 202 & 22 & 20 \\
\hline Winter et al. 2008 [34] & 330 & 8 & 29 & 21.7 & 71 & 251 & 76 & & 20 \\
\hline Amstrong IV 2006 & 210 & 36 & 75 & & & 64 & 135 & & 50 \\
\hline Amstrong IP 2006 & 205 & 38 & 78 & & & 62 & 127 & & \\
\hline Braicu et al. 2011 [36] & 415 & & & & & & & 33.5 & \\
\hline Eisenkop et al. 2003 [37] & 408 & 86 & 351 & 10 & 41 & 4 & 16 & & \\
\hline Chi et al. 2009 [38] & 210 & 27 & 57 & 52 & 110 & 20 & 43 & 19 & \\
\hline Eisenhauer1 [39] & 57 & 23 & 13 & 77 & 44 & 0 & 0 & 12 & \\
\hline Eisenhauer2 [39] & 122 & 30 & 37 & 70 & 85 & 0 & 0 & 7 & \\
\hline Chi et al. 2006 [40] & 441 & 15 & 67 & 36 & 169 & 49 & 233 & & 65 \\
\hline Chi et al. 2010 [41] & 141 & 30 & 42 & 60 & 85 & 10 & 14 & 22 & 48 \\
\hline Kobal et al. 2018 [42] & 108 & 54 & 58 & 17.6 & 19 & 29 & 31 & 22 & 36 \\
\hline Kang et al. 2011 [43] & 140 & 58 & 81 & 33.6 & 47 & 8.6 & 12 & & \\
\hline Kommos 2010 [44] & 267 & 47 & 126 & 32.6 & 87 & 20 & 57 & 33 & \\
\hline Magtibay et al. 2006 [45] & 66 & 9 & 6 & 32 & 21 & 18 & 12 & 28 & 40 \\
\hline Rafii et al. 2012 [46] & 180 & & & & & & & 11 & \\
\hline Rodriguez et al. 2013 [47] & 4312 & 20 & 860 & 40 & 1746 & 39 & 1647 & & 40 \\
\hline Salani et al. 2007 [48] & 102 & 39 & 40 & & & & & 47 & 35 \\
\hline Sperling et al. 2013 [49] & 3129 & 46 & 1296 & & & 54 & 1502 & & 40 \\
\hline Van Meurs et al. 2013 [50] & 336 & & & & & & & & 20 \\
\hline Wimberger et al. 2010 [51] & 573 & 12 & & 29 & & 58 & & & \\
\hline Winter et al. 2007 [52] & 1895 & 23 & 437 & 41 & 791 & 35 & 667 & & 40 \\
\hline Zivanovic et al. 2010 [53] & 526 & 18 & 93 & 42 & 221 & 40 & 212 & & \\
\hline Llueca and Escrig 2017 [54] & 90 & 82 & 74 & 6 & 5 & 14 & 11 & 31 & 39 \\
\hline Total patients & 25728 & & & & & & & & \\
\hline
\end{tabular}

\section{Cytoreductive rate}

The CCS rate was evaluated in 28 series with a total of 7450 patients included. The weighted average CCS was $38 \%$ and the quality limit was $<27 \%$ (Fig. 1).
The OCS rate was evaluated in 26 series with a total of 6933 patients included. The weighted average OCS was 33\% and the quality limit was $<23 \%$ (Fig. 2). 


\section{Complete cytoreductive surgery (CCS) rate (P-chart).}
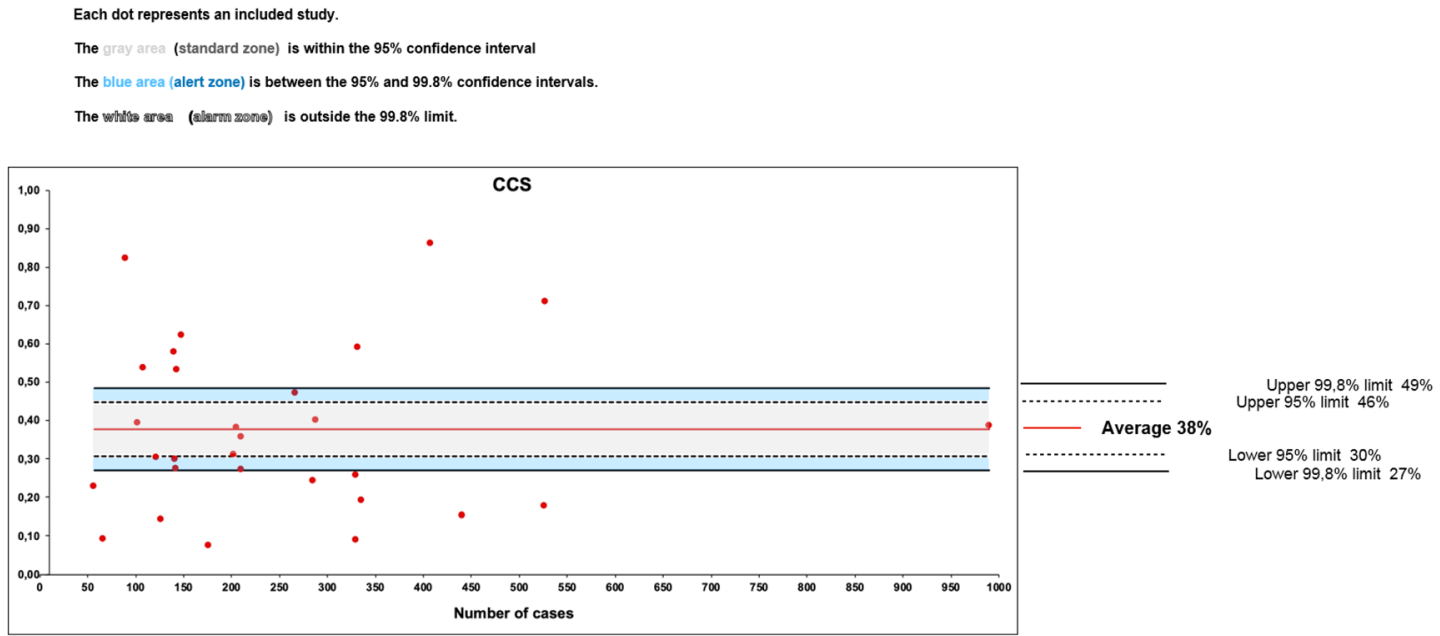

Fig. 1 Complete cytoreductive surgery (CCS) rate (P-chart). Each dot represents an included study. The gray area (standard zone) is within the 95\% confidence interval, the blue area (alert zone) is between the $95 \%$ and $99.8 \%$ confidence intervals, and the white area (alarm zone) is outside the $99.8 \%$ limit

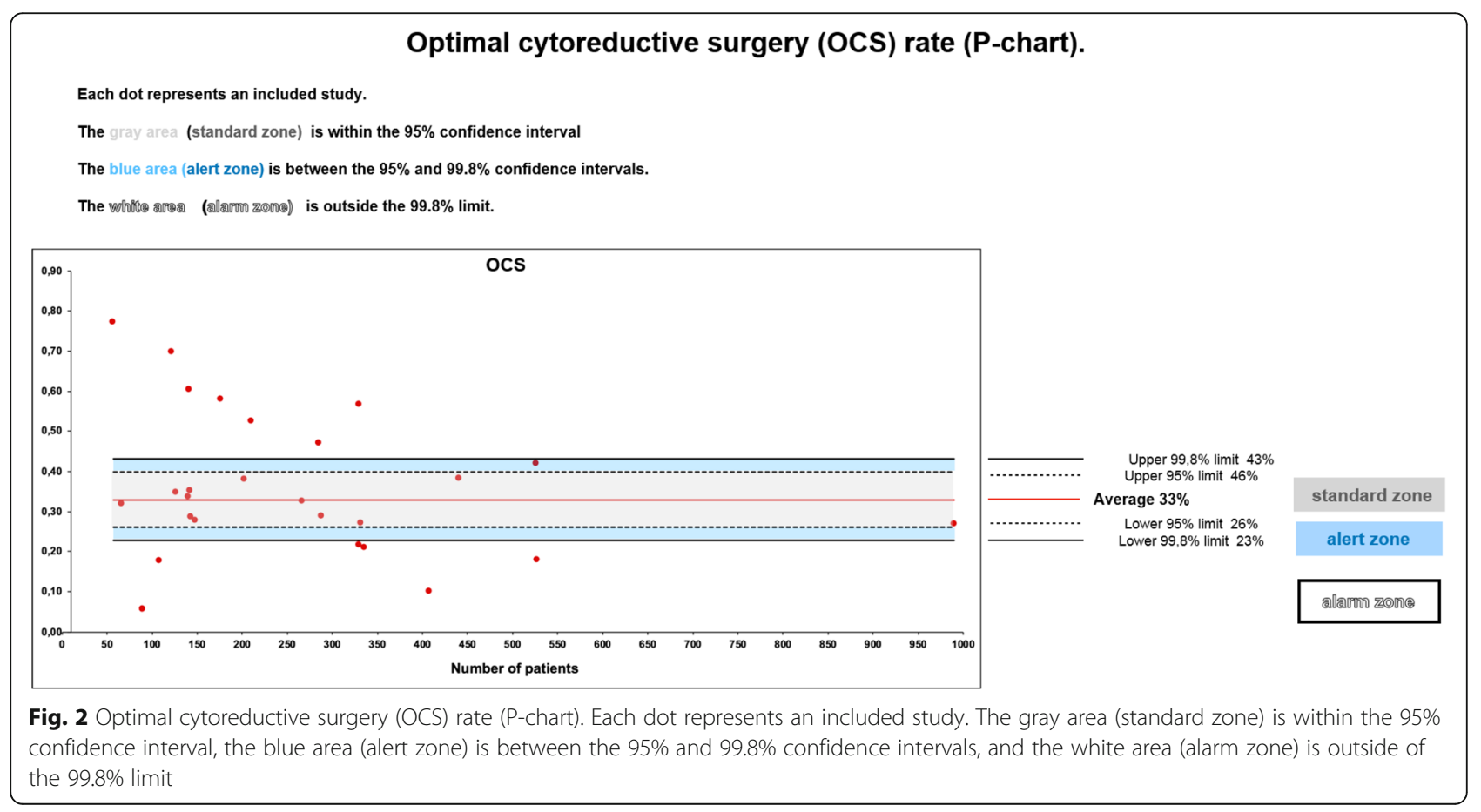


The SCS rate was evaluated in 27 series with a total of 7291 patients included. The weighted average SCS was $29 \%$ and the quality limit was > 39\% (Fig. 3).

\section{Morbidity}

Major complications were evaluated in 23 series with a total of 4519 patients evaluated. The weighted average morbidity was $23 \%$ and the quality limit was $>33 \%$ (Fig. 4).

\section{Survival}

The 5-year survival rate was evaluated in 19 series with a total of 5554 patients included. The weighted average overall survival (OS) was $37 \%$ and the quality limit was < 27\% (Fig. 5).

\section{Discussion}

A QI is a parameter that is used to measure the quality of medical assistance and provides information on aspects that can be improved. To evaluate the quality of a service or process, comparisons need to be established with some sort of guide or reference. This reference is what we define as a standard. Ideally, quality should be measured for populations with a common health care system and similar social customs (i.e., those in which different surgical teams have similar access to resources). Moreover, any risk-adjusted evaluation of the parameters involved in measuring quality should be taken into account for comparisons. In the absence of these ideal conditions, standards need to be identified in the data available in the literature, even if this means comparing systems as different as those in Japan, Europe, or the USA. This will at least offer a global perspective of what standards should be considered. Several studies have demonstrated the importance of hospital volume and mortality associated with treatments, and they have made important contributions to our understanding of the quality of surgical care. However, these parameters are insufficient $[55,56]$.

In 2016, the European Society of Gynaecological Oncology (ESGO) published an assessment of advanced ovarian cancer care based on formally developed QIs [9]. In this report, 10 QIs, including structural factors, clinical care process, treatment efficacy, and outcomes, were described. However quality limits where established only in two QIs, including the rate of complete surgical resection and the rate of primary debulking surgery. The quality limits were $>50 \%$ for both QIs. There are important methodological differences between the study by the ESGO and our study. The most relevant difference between studies is that the study by the ESGO identified QIs for a variety of factors based on estimations of a panel of ovarian cancer experts who were more focused on the accreditation of reference centers and health planning of ovarian cancer care. Our study identified outcome QIs and established AQLs for all items according to worldwide data. We used a different statistical methodology aimed to control variability that is inherent in the data of different institutions. Because these two studies covered different aspects of quality health care and methodology, they can be considered complementary.

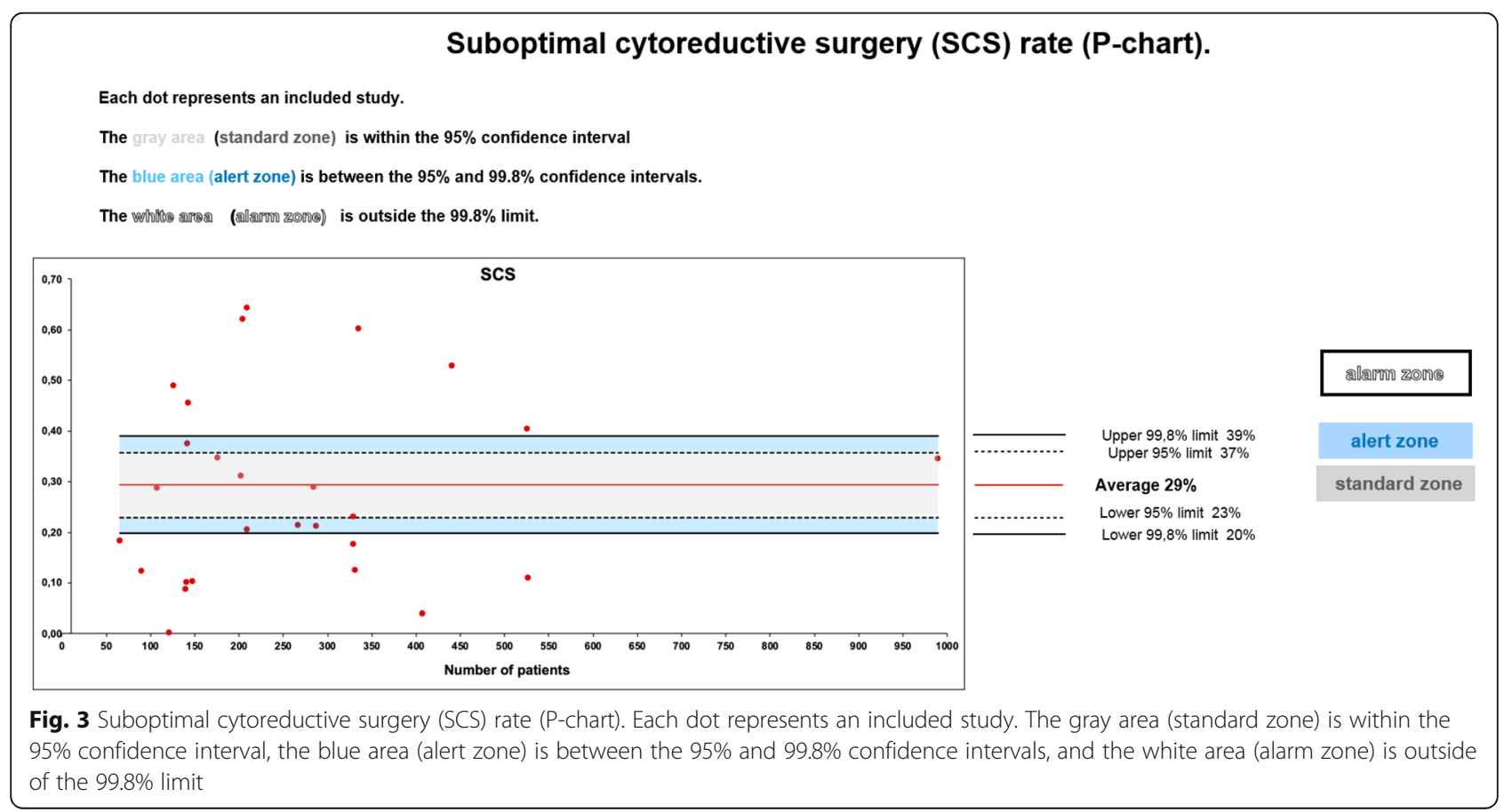




\section{Morbidity rate (P-chart)}
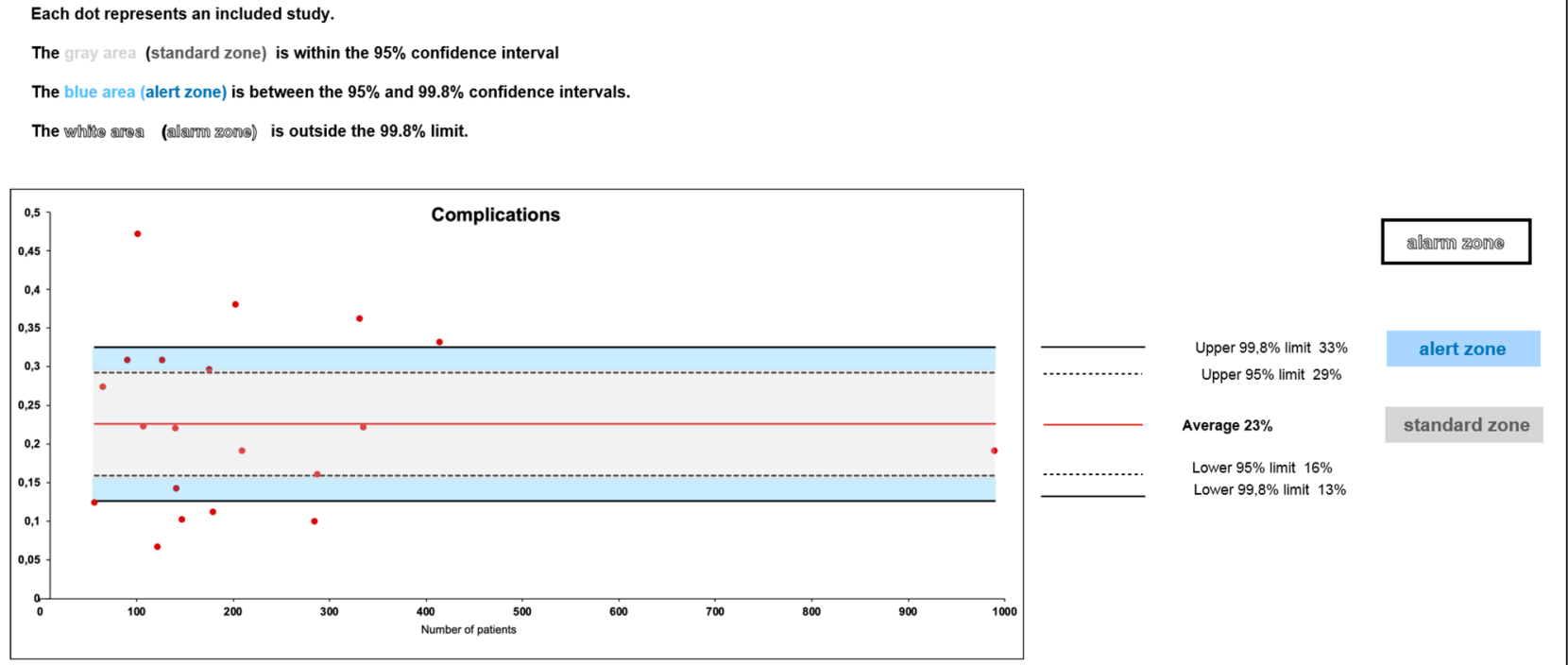

Fig. 4 Morbidity rate (P-chart). Each dot represents an included study. The gray area (standard zone) is within the 95\% confidence interval, the blue area (alert zone) is between the $95 \%$ and $99.8 \%$ confidence intervals, and the white area (alarm zone) is outside of the $99.8 \%$ limit

An investigation such as our study has several disadvantages when selecting QIs and series. With regard to QIs, there may be other indicators (e.g., operative time, blood transfusion, length of hospital stay, and costs). However, our selection was based on the most frequently published data available to obtain a relevant volume of series and cases for analysis. We used literature that was published in English between 2006 and 2018 for selection of the series. From 2005, there has been worldwide development and progress in this highly complex AOCS. We believe that our results offer a general view of what the clinical indicators should be, as

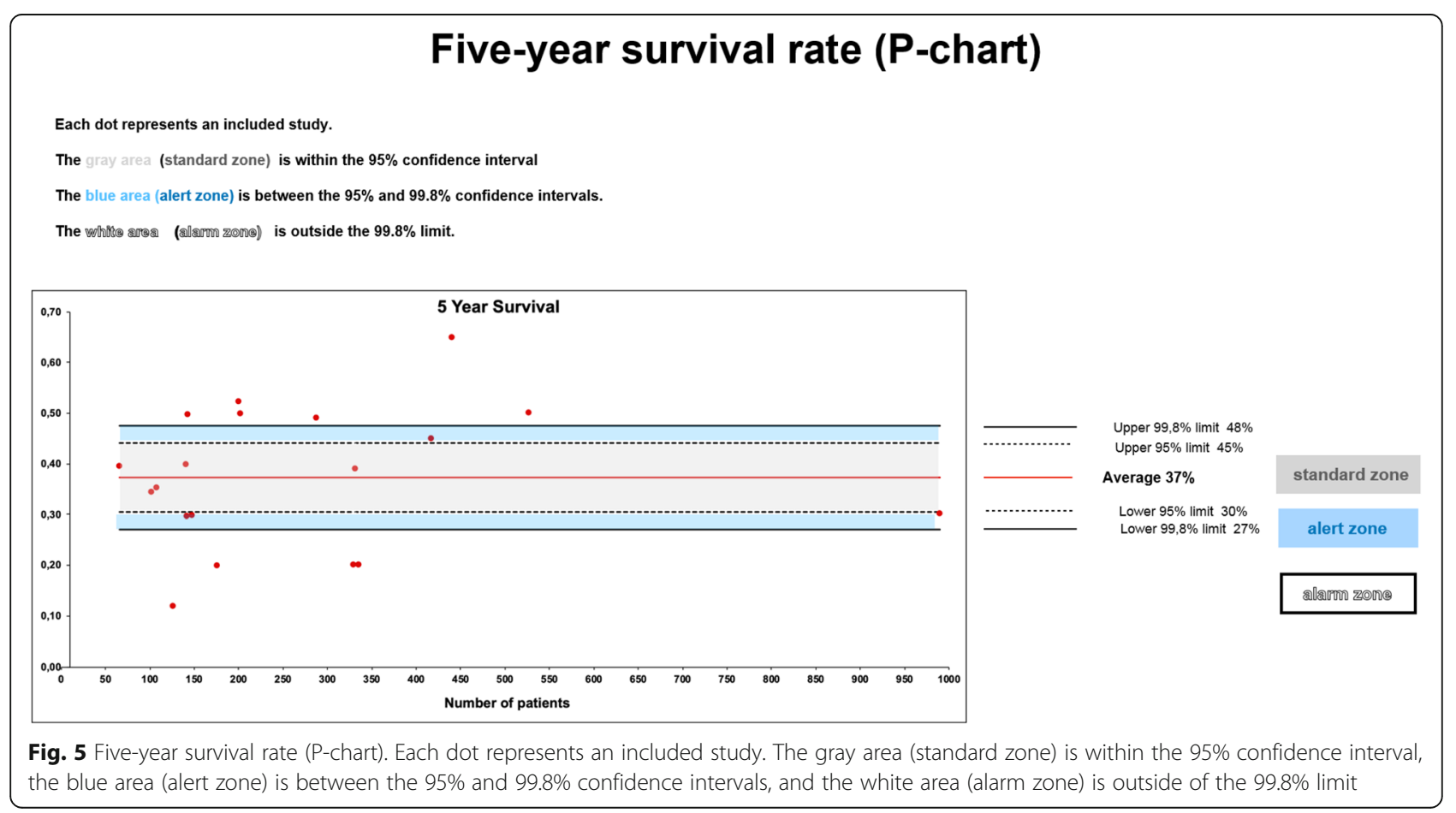


well as establishing AQLs that can be considered as standards.

In our study, standards and AQLs were obtained using weighted averages and confidence intervals of $99.8 \%$ and 95\%. Using this method, the probability of a particular observation being outside such limits is low if the evaluated procedure is under control (i.e., $p<0.002$ and $p<$ 0.05). In SPC terminology, such limits establish alarm $(99.8 \%)$ or alert $(95 \%)$ areas. When a result is either above or below the alarm zone, it may be considered either unfavorable or outstanding, depending on the nature of the evaluated variable. For CCS, a result below the alarm zone limit should be considered a bad outcome. However, for morbidity, when a result is below the alarm zone limit, it is considered to be an excellent result.

The CCS rates reported in the literature are highly variable, not only between regions, but within the same region. It is a common phenomenon that depends on the specialization of the working groups and their multidisciplinary organization. In our study, OCS and CCS quality limits were $71 \%$ in AOCS when considered together. This result is similar to that published recently by Park et al. where the percentage of OCS and CCS was $78 \%$ in the responses of a survey [57].

In our study, almost all of the graphs showed great variability of the results of the series that were investigated. This is called statistical overdispersion of the data [58]. The statistical phenomenon of overdispersion can be explained by two reasons. First, this phenomenon can be caused by the different definitions used in the studies, which may result in a case selection bias. Second, and much more likely, is that we did not compare similar practices.

In clinical practice, the FIGO (International Federation of Gynecology and Obstetrics) system is widely used to characterize and predict survival in ovarian cancer [59]. Intraperitoneal spread is the most typical presentation of stages III and IV ovarian cancer. Unfortunately, the FIGO system fails in characterization of tumor burden and in describing anatomical regions that are affected. Patients with stage IIIc ovarian cancer may have localized and easily resectable carcinomatosis, but they may also have extensive unresectable disease [60]. To objectively determine and quantify the tumor burden in these advanced ovarian cancer stages, some authors have described assessment tools in the field of surgical oncology. One of the most frequently used tool is the Peritoneal Cancer Index (PCI), which describes peritoneal carcinomatosis of all types [61]. Specifically for ovarian cancer, Fagotty, Allety, and Zivanovic [54] described some other assessment tools. The PCI provides useful information about the precise distribution and tumor volume, representing in detail the extent of peritoneal spread. We believe that the PCI should be incorporated as a complement to the FIGO stages for comparison of different series of different authors in a more objective manner. This process could decrease the rate of overdispersion of QIs.

In the same manner, drawing conclusions about morbidity is difficult if we are not speaking the same language. The overdispersion phenomenon is also observed between the lower and the upper quality limits of the morbidity rate in a P-chart. Recently, we found that major complications (grades III-IV of Clavien-Dindo) were much higher with a PCI $>20$ than those found with a $\mathrm{PCI}<10$ [2]. This finding could explain the enormous variability of data observed for the morbidity rate (Fig. 4). However, the aggressiveness of the tumor and the tumor biology itself could have some relevant role in this matter.

OS and progression-free survival (PFS) are important endpoints for evaluating new anti-cancer therapies. Although OS is considered to be the most clinically relevant endpoint in ovarian cancer treatment, it is affected by use of multiple post-progression therapies. Additionally, the time required to evaluate OS is often considerable. PFS, which measures the time to disease progression or death after treatment, is a useful endpoint because it can show a clinical benefit and is more rapidly assessable than OS [62]. Although the use of PFS is increasing considerably, most authors still refer to OS as a reference value. There are many factors that influence OS. In our study, the average 5-year OS rate was $37 \%$, and there was a large amount of variability (Fig. 5). As previously reported, the OS rate can rise to $>50 \%$ with a $\mathrm{PCI}<10$ and the inverse situation occurs with a PCI > $20[63,64]$.

This study has several limitations. First, this was a narrative retrospective review that combined data from clinical trials and retrospective institutional cohorts. Therefore, conclusions must be drawn with caution. Second, extracting data from the published series was difficult because of the enormous variability of the variables and the concepts included in the series. Therefore, there may have been some interpretation bias. Variability is inherent to any process, although beyond a certain variability, it becomes excessive. The key point to dealing with variability is delimiting and distinguishing normal and undesirable variability. The method used in this study allowed us to define the interval that discriminates variability from dispersion of data.

In conclusion, for advanced ovarian cancer surgery, five QIs were identified, the rates of CCS, OCS, SCS, complications and overall 5-year survival with AQLs of $<27 \%,<23 \%,>39 \%,>33 \%$, and $<27 \%$, respectively. For most physicians and surgeons, quality indicates good 
clinical outcomes and the effectiveness of treatment or surgery. In the clinical setting, quality should be measured according to objective clinical indicators, which was the goal of our study. Specific values that define quality standards in AOCS are essential.

\section{Acknowledgements}

We thank Ellen Knapp, PhD, from Edanz Group (www.edanzediting.com/ac) for editing a draft of this manuscript MUAPOS Working Group:

The members of the MUAPOS working group are as follows: Gomez-Quiles $L$, Escrig J, Serra A, Maiocchi K, Villarin A, Rodrigo-Aliaga M, Martinez S, Herrero C, Ruiz N, Izquierdo E, Bosso V, Maazouzi Y, Segarra B, Beltran MC, and Llueca A.

\section{Authors' contributions}

ALI and JE: conception and design, data acquisition, analysis and interpretation, writing of the manuscript; AS, MC, BS, AYM, and MS: acquisition of data and revision for important intellectual content. All authors have read and approved the final draft submitted.

\section{Funding}

This work received financial support for the design, analysis and editing this work, from de Medtronic University Chair for Training and Surgical Research, University Jaume I (UJI), Castellón, Spain and also supported by a research grant from ISCIII-FEDER (PI17/01945).

\section{Availability of data and materials}

Anonymized data can be provided upon reasonable request to corresponding author.

\section{Ethics approval and consent to participate}

All procedures performed in studies involving human participants were in accordance with the ethical standards of the local ethics and research committee and followed the Declaration of Helsinki guidelines. Informed consent for the analysis was obtained from the Ethics and Research Committee (No. 02223/2019) of our institution.

\section{Consent for publication}

Not applicable.

\section{Competing interests}

The authors declare that they have no competing interests.

\section{Author details}

'Department of Obstetrics and Gynecology, University General Hospital of Castellón, Av Benicasim s/n, 12004 Castellón, Spain. ${ }^{2}$ Multidisciplinary Unit of Abdominal Pelvic Oncology Surgery (MUAPOS), University General Hospital of Castellón, Av Benicasim s/n, 12004 Castellón, Spain. ${ }^{3}$ Department of Medicine, University Jaume I (UJI), Castellón, Spain. ${ }^{4}$ Department of Anesthesiology, University General Hospital of Castellón, Av Benicasim s/n, 12004 Castellón, Spain. ${ }^{5}$ Department of General Surgery, University General Hospital of Castellón, Av Benicasim s/n, 12004 Castellón, Spain.

\section{Received: 5 August 2020 Accepted: 26 October 2020}

\section{Published online: 25 November 2020}

\section{References}

1. Vergote I, Tropé CG, Amant F, Kristensen GB, Ehlen T, Johnson N, et al. Neoadjuvant chemotherapy or primary surgery in stage IIIC or IV ovarian cancer. N Engl J Med. 2010;36:943-53.

2. Llueca A, Serra A, Maiocchi K, Delgado K, Jativa R, Gomez L, Escrig J. Predictive model for major complications after extensive abdominal surgery in primary advanced ovarian cancer. Int J Womens Health. 2019;11:161-7.

3. Kalish BT, Vollmer CM, Kent TS, Nealon WH, Tseng JF, Callery MP. Quality assessment in pancreatic surgery: what might tomorrow require? J Gastrointest Surg. 2013;17:86-93.

4. Donabedian A. Evaluating the quality of medical care. Milbank Q. 2005:83: 691-729.
5. Lavoue V, Huchon C, Akladios C, et al. Management of epithelial cancer of the ovary, fallopian tube, and primary peritoneum. Short text of the French Clinical Practice Guidelines issued by FRANCOGYN, CNGOF, SFOG, and GINE CO-ARCAGY, and endorsed by INCa. Eur J Obstet Gynecol Reprod Biol. 2019, 236:214-23. https://doi.org/10.1016/j.ejogrb.2019.03.010 Epub 2019 Mar 15. PMID: 30905627.

6. Suh DH, Chang SJ, Song T, Lee S, Kang WD, Lee SJ, Roh JW, Joo WD, Yoon JH, Jeong DH, Kim HS, Lee SJ, Ji YI, Kim HJ, Lee JW, Kim JW, Bae DS. Practice guidelines for management of ovarian cancer in Korea: a Korean Society of Gynecologic Oncology Consensus Statement. J Gynecol Oncol. 2018;29(4):e56.

7. Wright A, Bohlke K, Armstrong DK, Bookman MA, Cliby WA, Coleman RL, et al. Neoadjuvant chemotherapy for newly diagnosed, advanced ovarian cancer: Society of Gynecologic Oncology and American Society of Clinical Oncology clinical practice guideline. J Clin Oncol. 2016;34(28):3460-73.

8. Karam A, Ledermann JA, Kim J-W, on behalf of the participants of the 5th Ovarian Cancer Consensus Conference, et al. Fifth ovarian cancer consensus conference of the gynecologic Cancer InterGroup: first-line interventions. Ann Oncol. 2017;28(4):711-7.

9. Querleu D, Planchamp MS, Chiva L, et al. European Society of Gynaecologic Oncology quality indicators for advanced ovarian cancer surgery. Int J Gynecol Cancer. 2016;26:1354-63.

10. Wimberger P, Lehmann N, Kimmig R, Burges A, Meier W, Du Bois A. Prognostic factors for complete debulking in advanced ovarian can- cer and its impact on survival. An exploratory analysis of a prospectively randomized phase III study of the Arbeitsgemeinschaft Gynaekologische Onkologie Ovarian Cancer Study Group (AGO-OVAR). Gynecol Oncol. 2007;106:69-74.

11. Cibula D, Verheijen R, Lopes A, Dusek L. ESGO Council. Current clinical practice in cytoreductive surgery for advanced ovarian cancer: a European survey. Int J Gynecol Cancer. 2011;21:1219-24.

12. Billson J, van der Merwe FH, Soeters RP. Current South African clinical practice in debulking surgery for ovarian cancer. Int J Gynecol Cancer. 2016; 26:1428-33.

13. Brand AH. Ovarian cancer debulking surgery: a survey of practice in Australia and New Zealand. Int J Gynecol Cancer. 2011;21:230-5.

14. Naik R, Bayne L, Founta C, Kehoe S, Rustin G, Fotopoulou C. Patient support groups identifying clinical equipoise in UK gynaecological oncol- ogy surgeons as the basis for trials in ultraradical surgery for advanced ovarian cancer. Int J Gynecol Cancer. 2016;26:91-4.

15. Barton DP, Adib T, Butler J. Surgical practice of UK gynaecological oncologists in the treatment of primary advanced epithelial ovarian cancer (PAEOC): a questionnaire survey. Gynecol Oncol. 2013;131:347-51.

16. Spiegelhalter DJ. Funnel plots for institutional comparison. Qual Saf Health Care. 2002:11:390-1.

17. Spiegelhalter DJ. Funnel plots for comparing institutional per- formance. Statist Med. 2005;24:1185-202.

18. Clavien PA, Barkun J, de Oliveira ML, Vauthey JN, Dindo D, Schulick RD, et al. The Clavien-Dindo classification of surgical complications: five-year experience. Ann Surg. 2009;250:187-96.

19. Du Bois A, Reuss A, Pujade-Lauraine, et al. Role of surgical outcome as prognostic factor in advanced epithelial ovarian cancer: a combined exploratory analysis of 3 prospectively randomized phase 3 multicenter trials. Cancer. 2009;115:1234-44.

20. Bookman MA, Brady MF, McGuire WP, et al. Evaluation of new platinumbased treatment regimens in advanced-stage ovarian cancer: a Phase III Trial of the Gynecologic Cancer Intergroup [published correction appears in J Clin Oncol. 2009 May 1;27(13):2305]. J Clin Oncol. 2009;27(9):1419-25.

21. Chang SJ, Bristow RE, Ryu HS. Impact of complete cytoreduction leaving no gross residual disease associated with radical cytoreductive surgical procedures on survival in advanced ovarian cancer. Ann Surg Oncol. 2012; 19:4059.

22. Chi DS, Musa F, Dao F, et al. An analysis of patients with bulky advanced stage ovarian, tubal, and peritoneal carcinoma treated with primary debulking surgery (PDS) during an identical time period as the randomized EORTC-NCIC trial of PDS vs neoadjuvant chemotherapy (NACT). Gynecol Oncol. 2012;124(1):10-4.

23. Colombo P, Mourregot A, Fabbro M, et al. Aggressive surgical strategies in advanced ovarian cancer: a monocentric study of 203 stage IIIC and IV patients. Europ J Surg Oncol. 2008;35(2):135-43.

24. Fagö-Olsen $\mathrm{CL}$, Ottesen $\mathrm{B}$, Kehlet $\mathrm{H}$, et al. Does neoadjuvant chemotherapy impair long-term survival for ovarian cancer patients? A nationwide Danish study. Gynecol Oncol. 2014;132(2):292-8. 
25. Fagotti A, Vizzielli G, Fanfani F, et al. Introduction of staging laparoscopy in the management of advanced epithelial ovarian, tubal and peritoneal cancer: impact on prognosis in a single institution experience. Gynecol Oncol. 2013;131(2):341-6.

26. Luyckx M, Leblanc E, Filleron T, et al. Maximal cytoreduction in patients with FIGO stage IIIC to stage IV ovarian, fallopian, and peritoneal cancer in dayto-day practice: a retrospective French multicentric study. Int J Gynecol Cancer. 2012;22:1337-43.

27. Peiretti M, Zanagnolo V, Aletti G, et al. Role of maximal primary cytoreductive surgery in patients with advanced epithelial ovarian and tubal cancer: aurgical and oncological outcomes. Single institution experience. Gynecol Oncol. 2010;119(2):259-64.

28. Rauh-Hain JA, Rodriguez N, Growdon WB, et al. Primary debulking surgery versus neoadjuvant chemotherapy in stage IV ovarian cancer. Ann Surg Oncol. 2012;19:959.

29. Rauh-Hain JA, Nitschmann CC, Worley MJ Jr, et al. Platinum resistance after neoadjuvant chemotherapy compared to primary surgery in patients with advanced epithelial ovarian carcinoma. Gynecol Oncol. 2013;129(1):63-8.

30. Rosen B, Laframboise S, Ferguson S, et al. The impacts of neoadjuvant chemotherapy and of debulking surgery on survival from advanced ovarian cancer. Gynecol Oncol. 2014;134:462-7.

31. Sehouli J, Savvatis K, Braicu E-I, et al. Primary versus interval debulking surgery in advanced ovarian cancer: results from a systematic single-center analysis. Int J Gynecol Cancer. 2010;20(8):1331-40.

32. Tropé CG, Elstrand B, Sandstad B, et al. Neoadjuvant chemotherapy, interval debulking surgery or primary surgery in ovarian carcinoma FIGO stage IV? Eur J Cancer. 2012;48(14):2146-54.

33. Vergote I, Trope CG, Amant F, et al. Neoadjuvant chemo- therapy or primary surgery in stage IIIC or IV ovarian cancer. N Engl J Med. 2010;363:943-53.

34. Winter W III, Maxwell GL, Tian C, et al. Tumor residual after surgical cytoreduction in prediction of clinical outcome in stage IV epithelial ovarian cancer: a Gynecologic Oncology Group Study. J Clin Oncol. 2008;26(1):83-9.

35. Armstrong DK, Bundy B, Wenzel L, et al. Intraperitoneal cisplatin and paclitaxel in ovarian cancer. N Engl J Med. 2006;354(1):34-43.

36. Braicu E, Sehouli J, Richter R, Pietzner K, Denkert C, Fotopoulou C. Role of histological type on surgical outcome and survival following radical primary tumour debulking of epithelial ovarian, fallopian tube and peritoneal cancers. Br J Cancer. 2011:105:1818-24.

37. Eisenkop SM, Spirtos NM, Friedman RL, Lin WC, Pisani AL, Perticucci S. Relative influences of tumor volume before surgery and the cytoreductive outcome on survival for patients with advanced ovarian cancer: a prospective study. Gynecol Oncol. 2003;90:390-6.

38. Chi DS, Eisenhauer EL, Zivanovic O, Sonoda Y, Abu-Rustum NR, Levine DA, et al. Improved progression-free and overall survival in advanced ovarian cancer as a result of a change in surgical paradigm. Gynecol Oncol. 2009; 114:26-31.

39. Eisenhauer EL, Abu-Rustum N, Sonoda Y, et al. The effect of maximal surgical cytoreduction on sensitivity to platinum-taxane chemotherapy and subsequent survival in patients with advanced ovarian cancer. Gynecol Oncol. 2008;108(2):276-81.

40. Chi DS, Eisenhauer EL, Lang J, Huh J, Haddad L, Abu-Rustum NR, et al. What is the optimal goal of primary cytoreductive surgery for bulky stage IIIC epithelial ovarian carcinoma (EOC)? Gynecol Oncol. 2006;103:559-64.

41. Chi DS, Zivanovic O, Kimberly L, et al. The incidence of major complications after the performance of extensive upper abdominal surgical procedures during primary cytoreduction of advanced ovarian, tubal, and peritoneal carcinomas. Gynecol Oncol. 2010;119(1):38-42.

42. Kobal B, Marco N, Branko C, et al. Primary debulking surgery versus primary neoadjuvant chemotherapy for high grade advanced stage ovarian cancer: comparison of survivals. Radiol Oncol. 2018;52(3):307-19.

43. Kang $\mathrm{S}$, Jong $\mathrm{YH}$, Hwang $\mathrm{JH}$, et al. Is neo-adjuvant chemotherapy a "waiver" of extensive upper abdominal surgery in advanced epithelial ovarian cancer? Ann Surg Oncol. 2011;18:3824.

44. Kommoss S, Rochon J, Harter P, et al. Prognostic impact of additional extended surgical procedures in advanced-stage primary ovarian cancer. Ann Surg Oncol. 2010;17:279.

45. Magtibay PM, Adams PB, Silverman MB, et al. Splenectomy as part of cytoreductive surgery in ovarian cancer. Gynecol Oncol. 2006;102(2):369-74.

46. Rafii A, Stoeckle E, Jean-Laurent M, Ferron G, Morice P, et al. Multi-center evaluation of post-operative morbidity and mortality after optimal cytoreductive surgery for advanced ovarian cancer. PLoS One. 2012;7(7):e39415.
47. Rodriguez N, Miller A, Richard SD, et al. Upper abdominal procedures in advanced stage ovarian or primary peritoneal carcinoma patients with minimal or no gross residual disease: an analysis of Gynecologic Oncology Group (GOG) 182. Gynecol Oncol. 2013;130:487-92.

48. Salani R, Zahurak ML, Santillan A, Giuntoli RL 2nd, Bristow RE. Survival impact of multiple bowel resections in patients undergoing primary cytoreductive surgery for advanced ovarian cancer: a case-control study. Gynecol Oncol. 2007;107:495-9.

49. Sperling C, Noer MC, Christensen IJ, Nielsen ML, Lidegaard $\varnothing$, Høgdall C. Comorbidity is an independent prognostic factor for the survival of ovarian cancer: a Danish register-based cohort study from a clinical database. Gynecol Oncol. 2013;129:97-102.

50. Van Meurs HS, Tajik P, Hof M, et al. Which patients benefit most from primary surgery or neoadjuvant chemotherapy in stage IIIC or IV ovarian cancer? An exploratory analysis of the European Organisation for Research and Treatment of Cancer 55971 randomised trial. Eur J Cancer. 2013;49(15): 3191-201.

51. Wimberger $P$, Wehling $M$, Lehmann $N$, et al. Influence of residual tumor on outcome in ovarian cancer patients with FIGO stage IV disease. Ann Surg Oncol. 2010;17:1642.

52. Winter WE 3rd, Maxwell GL, Tian C, Carlson JW, Ozols RF, Rose PG, et al. Prognostic factors for stage III epithelial ovarian cancer: a gynecologic oncology group study. J Clin Oncol. 2007;25:3621-7.

53. Zivanovic O, Sima CS, lasonos A, Hoskins WJ, Pingle PR, Leitao MM Jr, Sonoda Y, Abu-Rustum NR, Barakat RR, Chi DS. The effect of primary cytoreduction on outcomes of patients with FIGO stage IIIC ovarian cancer stratified by the initial tumor burden in the upper abdomen cephalad to the greater omentum. Gynecol Oncol. 2010;116(3):351-7.

54. Llueca A, Escrig E. Prognostic value of peritoneal cancer index in primary advanced ovarian cancer. Eur J Surg Oncol. 2017. https://doi.org/10.1016/j. ejso.2017.11.003.

55. Vollmer CM, Pratt W, Vanounou T, Maithel SK, Callery MP. Quality assessment in high-acuity surgery. Volume and mortality are not enough. Arch Surg. 2007;142:371-80.

56. Dimick JB, Welch HG, Birkmeyer JD. Surgical mortality as an indicator of hospital quality. The problem with small sample size. JAMA. 2004;292:847-51.

57. Park SJ, Kim J, Kim SN, et al. Practice patterns of surgery for advanced ovarian cancer: analysis from international surveys. Jpn J Clin Oncol. 2019; 49(2):137-45

58. Spiegelhalter DJ, Knill-Jones RP. Statistical and knowledge-based approaches to clinical decision-support systems, with an application in gastroenterology. J R Stat Soc Ser A Stat Soc. 1984;147:35-77.

59. Neijt J. Ovarian cancer: rethinking prognostic factors and chemotherapy. In: ASCO Educational Book; 1994. p. 214 20 .

60. Llueca A, Serra A, Rivadulla I, Gomez L, Escrig J, MUAPOS working group (Multidisciplinary Unit of Abdominal Pelvic Oncology Surgery). Prediction of suboptimal cytoreductive surgery in patients with advanced ovarian cancer based on preoperative and intraoperative determination of the peritoneal carcinomatosis index. World J Surg Oncol. 2018;16:37. https://doi.org/10. 1186/s12957-018-1339-0.

61. Sugarbaker PH, Jablonsky KA. Prognostic features of 51 colorectal and 130 appendiceal cancer patients with peritoneal carcinomatosis treated by cytoreductive surgery and intraperitoneal chemotherapy. Ann Surg. 1995; 221:124-32.

62. Chéreau $\mathrm{E}$, Ballester $\mathrm{M}$, Selle $\mathrm{F}$, et al. Comparison of peritoneal carcinomatosis scoring methods in predicting resectability and prognosis in advanced ovarian cancer. Am J Obstet Gynecol. 2010;201:178.e1-10.

63. Llueca A, Serra A, Delgado K, et al. A radiologic-laparoscopic model to predict suboptimal (or complete and optimal) debulking surgery in advanced ovarian cancer: a pilot study. Int J Womens Health. 2019;11:33342. https://doi.org/10.2147/IJWH.S198355.

64. Herzog TJ, Armstrong DK, Brady MF, et al. Ovarian cancer clinicaltrial endpoints: Society of Gynecologic Oncology white paper. Gynecol Oncol. 2014;132:8-17.

\section{Publisher's Note}

Springer Nature remains neutral with regard to jurisdictional claims in published maps and institutional affiliations. 